\title{
DILEMAS DO TRABALHO NO CAPITALISMO CONTEMPORÂNEO
}

\author{
Vera Lucia Navarro \\ Valquíria Padilha \\ Universidade de São Paulo, Ribeirão Preto, Brasil
}

\begin{abstract}
RESUMO: Partindo da concepção marxiana de trabalho que compreende a atividade laboral como uma atividade vital, autodeterminada, dotada de sentido - o que não ocorre sob a lógica do capital -, buscamos neste artigo apontar algumas das principais mudanças ocorridas no universo do trabalho no século XX e suas consequiências para a classe trabalhadora. O que pretendemos destacar é que ao longo do desenvolvimento do processo de trabalho - do taylorismo ao toyotismo - as transformações não significaram ruptura com o caráter capitalista do modo de produção e com seu complexo plano ideológico de controle da subjetividade do trabalhador. Exemplos disso são a apologia do individualismo, o aumento do desemprego, da intensificação e da precarização do trabalho, que marcam o mundo do trabalho na sociedade contemporânea.
\end{abstract}

PALAVRAS-CHAVE: trabalho, reestruturação produtiva, subjetividade do trabalhador.

\section{DILEMMAS OF WORK IN CONTEMPORARY CAPITALISM}

ABSTRACT: Starting from the Marxist conception of work, which considers labor as a vital, self-determined and meaningful activity - which is not the case in the logic of capital -, in this article, we attempt to indicate some of the main changes that occurred in the universe of work in the $\mathrm{XX}^{\mathrm{th}}$-century and their consequences for the working class. What we aim to highlight is that, throughout the development of the work process - from Taylorism to Toyotism transformations did not mean rupture with the capitalist character of the production mode, nor with its complex ideological plan to control the subjectivity of workers. Examples include the apology of individualism and the increase in unemployment, intensification and precariousness of work, which mark the world of work in contemporary society. KEYWORDS: work, production restructuring, subjectivity of workers.

Não se deve tirar e conclusão de que minhas opiniões inspiram-se em nostalgia de uma época que não pode mais voltar. Pelo contrário, minhas opiniões sobre o trabalho estão dominadas pela nostalgia de uma época que ainda não existe (Braverman, 1987, p. 18).

Foram marcantes as transformações ocorridas no mundo do trabalho na virada do século XX para o XXI e o crescimento em escala mundial do desemprego é, certamente, a face mais perversa deste quadro. Constatamos que, apesar de todo o desenvolvimento científico e tecnológico, de todas as importantes inovações operadas na base técnica dos processos produtivos, houve pouco alívio na labuta humana. Em realidade, tais mudanças no conjunto da economia e da sociedade resultantes da reestruturação produtiva, que ganhou maior visibilidade a partir dos anos 1990, acabaram por intensificar a exploração da força de trabalho e precarizar o emprego.

Neste cenário, podemos observar uma contradição marcante: enquanto parte significativa da classe trabalhadora é penalizada com a falta de trabalho, outros sofrem com seu excesso. Além da precarização das condições de trabalho, da informalização do emprego, do recuo da ação sindical crescem, em variadas atividades, os problemas de saúde, tanto físicos quanto psíquicos, relacionados ao trabalho. A busca da compreensão desta questão nos re- mete à discussão acerca das mudanças do processo de trabalho no capitalismo que expressam a necessidade constante de reprodução ampliada do capital ao longo de sua história. Para tentarmos entender como isto se processa se faz necessária retomada de alguns conceitos que nos possibilitam acompanhar o movimento e as transformações operadas no trabalho sob o capitalismo.

\section{Revendo os significados do trabalho}

Entendemos que o trabalho tem caráter plural e polissêmico e que exige conhecimento multidisciplinar; é também a atividade laboral fonte de experiência psicossocial, sobretudo dada a sua centralidade na vida das pessoas: é indubitável que o trabalho ocupa parte importante do espaço e do tempo em que se desenvolve a vida humana contemporânea. Assim, ele não é apenas meio de satisfação das necessidades básicas, é também fonte de identificação e de auto-estima, de desenvolvimento das potencialidades humanas, de alcançar sentimento de participação nos objetivos da sociedade. Trabalho e profissão (ainda) são senhas de identidade.

Compreendemos que as pessoas, apesar de as transformações que testemunhamos hoje, continuam ancorando sua existência na atividade laboral, mesmo aquelas que se encontram em situação de desemprego. 
A centralidade do trabalho dá-se não só na esfera econômica (o trabalho é a fonte de renda da maioria da população mundial) como também na esfera psíquica - o que, certamente, representa um paradoxo, uma vez que a atividade laboral ainda parece ser uma importante fonte de saúde psíquica (tanto que sua ausência, pelo desemprego ou pela aposentadoria, é causa de abalos psíquicos) ao mesmo tempo em que se registram cada vez mais pesquisas que evidenciam o trabalho como causa de doenças físicas, mentais e de mortes ${ }^{1}$. É preciso perguntar: que tipo de trabalho adoece corpo e mente e até mata? Certamente, não é o trabalho criativo, produtivo, prazeroso, que deveria ser central na vida das pessoas.

Quando afirmamos ser o trabalho central na vida das pessoas, partimos do princípio marxiano ${ }^{2}$ de que é por meio do trabalho que o homem torna-se um ser social. Assim, o trabalho é compreendido como momento decisivo na relação do homem com a natureza, pois ele modifica a sua própria natureza ao atuar sobre a natureza externa quando executa o ato de produção e de reprodução. Nesse sentido, o trabalho é um ato que pressupõe a consciência e o conhecimento dos meios e dos fins aos quais se pretende chegar. Pode-se afirmar que não há trabalho humano sem consciência (enquanto finalidade), na medida em que todo trabalho busca a satisfação de uma necessidade.

Nas palavras de Marx (1989a, p. 208):

O processo de trabalho, que descrevemos em seus elementos simples e abstratos, é atividade dirigida com o fim de criar valores-de-uso, de apropriar os elementos naturais às necessidades humanas; é condição necessária do intercâmbio material entre o homem e a natureza; é condição natural eterna da vida humana [grifos nossos], sem depender, portanto, de qualquer forma dessa vida, sendo antes comum a todas as suas formas sociais.

Vale lembrar que quando se fala da dimensão do trabalho como categoria primeira está se pensando em atividade que cria valor-de-uso e que trava relações entre o homem e a natureza, ou seja, referimo-nos ao trabalho concreto - que é divergente do trabalho abstrato, uma atividade estranhada e fetichizada, que cria valor-de-troca. Com o desenvolvimento do capitalismo, a dimensão do trabalho concreto - que produz objetos úteis - perde espaço para a dimensão do trabalho abstrato.

Nas sociedades contemporâneas, o uso perde valor para a troca; os produtos não são mais produzidos prioritariamente para serem usados até o seu fim. Esta é uma tendência que se acentua nas sociedades capitalistas nas quais a descartabilidade das mercadorias é cada vez mais prematura. O descarte, independentemente da qualidade da mercadoria, é induzido para que novos produtos sejam comprados, o que leva os produtos para o lixo muito antes de esgotada a sua vida útil. Para Mészáros (1989) o modo capitalista de produção é inimigo da durabilidade, portanto deve solapar as práticas produtivas orientadas para a durabilidade, inclusive comprometendo deliberadamente a qualidade.

O capitalismo traz consigo uma série de contradições, muitas delas relacionadas ao mundo do trabalho. Ao mesmo tempo em que o trabalho é a fonte de humanização e é o fundador do ser social, sob a lógica do capital se torna degradado, alienado, estranhado. O trabalho perde a dimensão original e indispensável ao homem de produzir coisas úteis (que visariam satisfazer as necessidades humanas) para atender as necessidades do capital. Sob o capitalismo, explicou Marx, o trabalhador decai à condição de mercadoria e a sua miséria está na razão inversa da magnitude de sua produção. Nas suas palavras:

\begin{abstract}
O trabalhador se torna tão mais pobre quanto mais riqueza produz, quanto mais a sua produção aumenta em poder e extensão. O trabalhador se torna uma mercadoria tão mais barata quanto mais mercadorias cria. Com a valorização do mundo das coisas aumenta em proporção direta a desvalorização do mundo dos homens. O trabalho não produz só mercadorias; produz a si mesmo e ao trabalhador como uma mercadoria [grifos do autor], e isto na proporção em que produz mercadorias em geral (Marx, 1989b, p. 148).
\end{abstract}

O produto do trabalho aparece, no final, como algo alheio ou estranho ao trabalhador, como um objeto que não lhe pertence. "O trabalhador coloca a sua vida no objeto; mas agora ela não pertence mais a ele, mas sim ao objeto" (Marx, 1989b, p. 150).

Quando se faz a crítica à sociedade capitalista deve-se, então, passar pela crítica do trabalho abstrato, pois é ele que contém a dimensão de estranhamento. Quanto mais esta dimensão do trabalho predomina numa sociedade, mais esta sociedade é estranhada. O estranhamento é o afastamento do homem de sua essência humana, é a sua conversão em coisa, sua reificação. Uma sociedade estranhada é uma sociedade que cria, por sua lógica estrutural, barreiras sociais para o livre desenvolvimento das potencialidades humanas. O fenômeno do estranhamento se apóia na "histórica apropriação desigual dos produtos do trabalho humano" (Ranieri, 2001, p. 61). Sobre essa questão, o autor explica que "na medida em que o trabalho estranhado rebaixa a atividade humana a mero meio de subsistência, a própria vida humana transforma-se num meio [itálicos do autor] de efetivação da atividade estranhada" (Ranieri, 2001, p. 62).

Em contrapartida, uma sociedade emancipada é aquela que conseguiu abortar todas as formas de estranhamento do ser, inclusive e principalmente o trabalho assalariado abstrato e todas as formas de propriedade privada. Assim, 
o que defendemos é que o homem não pode abdicar da dimensão concreta do trabalho, sob pena de perder a principal referência do seu caráter de humano e de ser social. Os riscos desta perda acontecer são constantes, sobretudo quando entendemos e levamos em consideração o caráter do fetichismo presente na produção das sociedades capitalistas.

O fetiche da mercadoria é a aparência que se sobrepõe à essência, é o mundo das coisas como objetivo final, provocando o comprometimento e/ou supressão da subjetividade: a "coisa" sufoca o "humano". O fetichismo - este caráter misterioso das mercadorias - provém do fato de que elas ocultam a relação social entre os trabalhos individuais dos produtores e o trabalho total. Nas palavras de Marx (1989a, p. 80-81): "Uma relação social definida, estabelecida entre os homens, assume a forma fantasmagórica de uma relação entre coisas."

O estranhamento e o fetichismo fazem parte do mesmo processo de coisificação dos sujeitos. Nas palavras de Silveira (1989, p. 50):

\begin{abstract}
... na atividade alienada, em que o homem, a classe, o indivíduo não se apropriam do resultado de sua atividade vital, a energia vital dispendida se torna própria do 'objeto', que rigorosamente se torna coisa no sentido de ter adquirido vida própria, um poder autônomo: o estranhamento, o alheamento... É neste sentido também... que esse sujeito é determinado, é limitado, é, radicalmente falando, coisificado, posto pela coisa que se apropriou do que era próprio ao sujeito da atividade vital. A coisa, o capital, a mercadoria, o dinheiro pondo sujeitos físicos [grifos do autor], isto é, sujeitos de que dependem - elas, as coisas - para se reproduzirem como tais.
\end{abstract}

O fetichismo da mercadoria e o controle que o capital exerce sobre o trabalho humano, no capitalismo, são causas diretas da alienação ou estranhamento dos trabalhadores. Cada vez mais o trabalhador - que, como "ser genérico", representa toda a humanidade - encontra-se estranhado. Este estranhamento intensifica-se com o desenvolvimento do capitalismo.

\section{$O$ desenvolvimento do trabalho no século $X X$}

A principal abordagem desenvolvida aqui é a de que o trabalho é o elemento fundante do ser social, é o ponto de partida da humanização. Diante disso, podemos perguntar: quais são as implicações das transformações do mundo do trabalho para a vida dos trabalhadores?

$\mathrm{O}$ avanço das forças produtivas (a ciência e a técnica) intensifica o estranhamento. O desenvolvimento das forças produtivas é um processo contraditório na medida em que capacita o capital ao mesmo tempo em que suprime o trabalho. A lógica deste avanço tecnológico é a lógica do capital, assim, não são a ciência e a técnica perversas em si. Isso fica claro quando conhecemos a história do surgimento das fábricas, conforme nos sugere Decca (1988, p. 7). Ele afirma que "dentre todas as utopias criadas a partir do século XVI, nenhuma se realizou tão desgraçadamente como a da sociedade do trabalho." A dimensão crucial da glorificação do trabalho deu-se com o surgimento da fábrica mecanizada, que aparecia aos olhos do mundo ocidental como a nova ilusão de que não haveria limites para a produtividade humana.

Decca (1988) afirma que é preciso encontrar a fábrica em todos os lugares em que se teve a intenção de disciplinar e assujeitar o trabalhador. Isso quer dizer que o sucesso da fábrica não foi, como se pode pensar, a mecanização e o desenvolvimento tecnológico, mas sim o fato de ela ter sido um locus privilegiado da disciplinarização dos trabalhadores que acabaram por introjetar dentro de cada um o relógio moral do desenvolvimento capitalista.

O que o autor assevera é que a divisão do trabalho criada para o funcionamento da fábrica significou a apropriação dos saberes (anteriormente pertencentes aos artesãos) por meio de sutis mecanismos de controle social. A tecnologia é vista, então, como mais uma forma de controle social. A imposição da noção de "tempo útil" parece ser um bom exemplo disso, na medida em que prevalece, cada vez mais, a idéia "moralizante" de que não se pode perder tempo, de que tempo é dinheiro. Esta introjeção definitiva da imagem e do valor do tempo como moeda de mercado $^{3}$ é uma ilustração de que são dominantes as idéias da classe dominante.

Marglin (1989, p. 41) afirma:

... a origem e o sucesso da fábrica não se explicam por uma superioridade tecnológica, mas pelo fato dela despojar o operário de qualquer controle e de dar ao capitalista o poder de prescrever a natureza do trabalho e a quantidade a produzir. A partir disso, o operário não é livre para decidir como e quanto quer trabalhar para produzir o que lhe é necessário; mas é preciso que ele escolha trabalhar nas condições do patrão ou não trabalhar, o que não the deixa nenhuma escolha.

Os capitalistas reuniram os trabalhadores em fábricas muito mais por uma questão organizacional que tecnológica. No entanto, a técnica não deve ser entendida como neutra: ela serviu e continua servindo aos interesses de controle e hierarquia do capital. O capital conseguiu que a ciência se colocasse a seu serviço, o que se deu num processo de "docilização" da mão-de-obra (Decca, 1988). A apropriação do saber - inicialmente do artesão e posteriormente do operário - pelos capitalistas nas fábricas é uma das formas deste estranhamento que continua se manifestando até os dias atuais.

Os relatos de Simone Weil, professora de filosofia na França que optou por trabalhar como operária na fábrica para sentir na pele o sofrimento do trabalhador, descreve 
sensações interessantes e explica o que a vida na fábrica fez com ela:

\section{... E não creio que tenham nascido em mim senti- mentos de revolta. Não, muito ao contrário. Veio o que era a última coisa do mundo que eu esperava de mim: a docilidade. Uma docilidade de besta de carga resignada. Parecia que eu tinha nascido para esperar, para receber, para executar ordens - que nunca tinha feito senão isso -, que nunca mais faria outra coisa. Não tenho orgulho em confessar isso. É a espécie de sofrimento de que nenhum operário fala; dói demais, só de pensar (Weil apud Bosi, 1996, p. 79).}

A história da organização do trabalho é a história do desenvolvimento tecnológico em favor da acumulação capitalista ao mesmo tempo em que é a história do sofrimento dos trabalhadores. Os avanços científicos ocorridos em nome do progresso não conseguiram eliminar as formas de exploração física e psíquica dos trabalhadores, nas fábricas ou fora delas. As técnicas de organização da produção e do trabalho, baseadas nos princípios taylorista, fordista e toyotista só fizeram aumentar estas formas de exploração.

\section{Taylorismo, Fordismo e Toyotismo: formas de intensificação e controle do trabalho}

Ao longo de todo o desenvolvimento do processo de trabalho no capitalismo, o que podemos observar é a perda progressiva do controle do trabalhador sobre o processo produtivo e, em consequiência, a perda de controle sobre seu próprio trabalho. O que varia, em diferentes momentos, são as formas disto se objetivar.

O taylorismo não promoveu mudanças importantes na base técnica do processo de trabalho, sua preocupação foi com o desenvolvimento dos métodos e organização do trabalho. Ele aprofundou a divisão do trabalho introduzida pelo sistema de fábrica, assegurando definitivamente o controle do tempo do trabalhador pela gerência, o que significou uma separação extrema entre concepção e execução do trabalho.

De acordo com Braverman (1987), o que Taylor buscava não era a melhor maneira de trabalhar em geral mas uma resposta ao problema específico de como controlar melhor o trabalho alienado, ou seja, a força de trabalho comprada e vendida.

Para Braverman (1987), o controle do trabalho ao longo da história da gerência sempre foi o aspecto essencial, entretanto, a partir de Taylor esta questão adquiriu dimensões sem precedentes. Em geral, antes de Taylor, admitia-se que a gerência tinha o direito de controlar o trabalho, o que usualmente significava apenas a fixação de tarefas, com pouca interferência direta na maneira do trabalhador executá-las. Com Taylor essa prática foi invertida, foi substituída pelo seu oposto: ele alegava que a gerên- cia se tornaria um empreendimento limitado e frustrado se deixasse ao trabalhador qualquer tipo de decisão sobre o trabalho.

Seu 'sistema' era tão-somente um meio para que a gerência efetuasse o controle do modo concreto de execução de toda a atividade no trabalho, desde a mais simples à mais complicada. Nesse sentido, ele foi pioneiro de uma revolução muito maior na divisão do trabalho que qualquer outra havida (Braverman, 1987, p. 86).

O fordismo continuou requerendo este tipo de trabalhador estranhado que o taylorismo havia evidenciado. ${ }^{4}$ Ford mantém o essencial do taylorismo e aperfeiçoa o método introduzindo a linha de montagem e um novo modo de gerir a força de trabalho, com destaque aos incentivos dados aos trabalhadores através de aumento dos níveis salariais.

A história registra, no entanto, uma significativa resistência operária ao fordismo, uma vez que os trabalhadores sentiram a perda de seu savoir-faire e sentiram o peso de um trabalho puramente mecanizado, rotinizado, gerando um alto índice de absenteísmo, aumento de paralisações e sabotagens. Em contraposição, houve considerável aumento de salário para amenizar temporariamente os problemas com a força de trabalho.

\section{Crise do padrão Taylorista-Fordista e a propagação do Toyotismo}

Nos anos 1970 o padrão de regulação taylorista-fordista começa a dar sinais de esgotamento em meio à crise estrutural vivida pelo capitalismo nesse período. O taylorismo e o fordismo passam a conviver ou mesmo a ser substituídos por outros modelos considerados mais "enxutos" e "flexíveis", melhor adequados às novas exigências capitalistas de um mercado cada vez mais globalizado. É a partir dos anos 1980 que se observa o acirramento da chamada reestruturação produtiva. Em um cenário de maior competitividade as empresas, visando a redução dos custos de produção, a maior variabilidade de suas mercadorias, a melhoria da qualidade de seus produtos e serviços e de sua produtividade, investiram em mudanças de ordem tecnológica e organizacionais, que repercutiram negativamente nas relações e condições de trabalho.

Novas formas de organização do trabalho "mais flexíveis", alternativas ao taylorismo-fordismo considerado muito "rígido", emergiram em várias partes do mundo, mesclando, fundindo-se ou mesmo superando a(s) anteriormente predominante(s) (Antunes, 1995). Alguns estudos chegam mesmo a afirmar a existência de um novo paradigma de produção industrial alternativo ao fordismo. São exemplos destas novas experiências o modelo sueco, o modelo italiano e o modelo japonês 5 . No entanto, foi este último que conseguiu maior capacidade de propagação. 
Os métodos produtivos japoneses aparecem sempre como

... a materialização de um novo sistema de organização, desenvolvimento e competitividade industrial, como exemplo de modernidade capitalista a ser reproduzido pelas empresas que pretendam chegar à condição de world class company (empresa de categoria mundial). O toyotismo é a marca de um modelo de exploração vendido mundialmente e adaptado a qualquer situação nacional. Na visão dos capitalistas $e$ da maior parte dos pesquisadores, as relações de produção deste modelo japonês são também a própria realização da harmonia entre capital e trabalhador (Martins, 1994, p. 124).

O sistema Toyota, ou como prefere Coriat (1994, p. 24) o Ohnismo, ${ }^{6}$ "constitui um conjunto de inovações organizacionais cuja importância é comparável ao que foram em suas épocas as inovações organizacionais trazidas pelo taylorismo e pelo fordismo." O objetivo maior de seu método é produzir a baixos custos pequenas séries de produtos variados. Um dos primeiros problemas de Ohno, no início de seu empreendimento, foi a questão dos estoques, visto que o Japão não é um país que dispõe de vastos espaços como os Estados Unidos. Segundo Coriat, duas descobertas nascem a partir desse problema: a "fábrica mínima" a "administração pelos olhos". A primeira está relacionada com o fato de que atrás do estoque há um "excesso de pessoal", o que leva à conclusão de que se o estoque é permanente, há por detrás dele um excesso de equipamento. É nas entrelinhas deste princípio que, segundo Coriat (1994, p. 33):

... se desenha aquilo que seríamos tentados a designar como a 'fábrica mínima', a fábrica reduzida às suas funções, equipamentos e efetivos estritamente necessários para satisfazer a demanda diária ou semanal. Observe-se também que, no espírito de Ohno, a fábrica mínima é primeiro e antes de tudo a fábrica de pessoal mínimo.

Na Toyota de Ohno, o conceito de economia é indissociável da busca da 'redução de efetivos' e da 'redução de custos'. Obviamente, não se pensa nos altos custos psicossociais dessa política.

A segunda descoberta de Ohno é o método de "gestão pelos olhos". A meta a alcançar é a eliminação de tudo que for considerado "supérfluo", dos "excessos gordurosos", tudo aquilo que uma fábrica pode dispensar. Nasce, então, segundo Coriat (1994, p. 36), a fábrica "magra", transparente e flexível que se opõe à fábrica fordista qualificada como "gorda". O ponto forte dessa "fábrica mínima" é o just in time que organiza a produção de modo a fabricar os produtos apenas na quantidade e no momento de serem escoados, o que pressupõe estoque mínimo e número reduzido de operários.
Outra característica do modelo japonês bastante difundida no meio empresarial e, em parte do meio acadêmico, diz respeito à qualificação do trabalhador. Contrariamente ao operário do taylorismo/fordismo que desempenhava tarefas altamente simplificadas, repetitivas, monótonas e embrutecedoras, o trabalhador no toyotismo, estaria transformando em um trabalhador "altamente qualificado", "polivalente" "multiprofissional". Na prática, várias pesquisas demonstram que estas mudanças, de forma geral, ao invés de qualificar o trabalhador o sobrecarrega com mais trabalho.

O que se observa é que o toyotismo mantém as formas objetivas de exploração do trabalho e amplia as formas subjetivas desta exploração.
... o taylorismo e o fordismo tinham uma concepção muito linear, onde a Gerência Científica elaborava e o trabalhador manual executava. O toyotismo per- cebeu, entretanto, que o saber intelectual do trabalho é muito maior do que ofordismo e taylorismo imagi- navam, e que era preciso deixar que o saber inte- lectual do trabalho florescesse e fosse também ele apropriado pelo capital (Antunes, 1999, p. 206).

Para Harvey (1993) esse novo quadro ("acumulação flexível") onde o mercado de trabalho passa por uma reestruturação radical possibilita maior controle do trabalho pelos empregadores, na medida em que o conjunto da força de trabalho sai muito mais enfraquecido desse processo.

Diante da forte volatilidade do mercado, do aumento da competição e do estreitamento das margens de lucro, os patrões tiraram proveito do enfraquecimento do poder sindical e da grande quantidade de mão-deobra excedente (desempregados e sub-empregados) para impor regimes e contratos de trabalho mais flexíveis (Harvey, 1993, p. 143).

Apesar de a luta de classes estar presente nas relações antagônicas entre capital e trabalho no século XX e agora no século XXI, a organização coletiva de trabalhadores, no mundo e no Brasil em particular, vem enfrentando impasses importantes. O enfraquecimento dos sindicatos das últimas décadas não tem conseguido impedir o processo de precarização do trabalho, conforme analisamos nesse artigo. Segundo Ramalho (1997, p. 86):

O movimento sindical passa pelas dificuldades de lidar com uma situação fabril à qual políticas e estratégias de ação sindical parecem impotentes para deter a destruição de direitos e se relacionar com uma força de trabalho de características diversas daquelas encontradas no pátio das grandes empresas.

As metamorfoses do trabalho ferem não só os direitos e a subjetividade do trabalhador, com também suas formas de organização na luta contra o capital. Conforme afirma Antunes (1997, p. 72), desde os anos 1980, o sindicalismo vem-se configurando como um sindicalismo "de negocia- 
ção" que aceita a ordem do capital e do mercado, que abandona a luta pelo socialismo e pela emancipação e que debate "no universo da agenda e do ideário neoliberal."

\section{Considerações Finais}

Considerando o conjunto das transformações operadas no mundo do trabalho no último século - do taylorismo ao toyotismo - podemos pensar que, conforme sugere Tomaney (citado por Antunes, 1999, p. 49):

as mudanças no processo capitalista de trabalho não são tão profundas, mas exprimem uma contínua transformação dentro do mesmo processo de trabalho, atingindo sobretudo as formas de gestão e o fluxo de controle, mas levando freqüentemente à intensificação do trabalho.

O que pretendemos destacar é que ao longo do desenvolvimento do processo de trabalho nos séculos XIX e $\mathrm{XX}$, apesar de algumas transformações e crises, não houve uma verdadeira ruptura com o caráter capitalista do modo de produção e com seu complexo plano ideológico de fragmentação da subjetividade para facilitar a manutenção de seu projeto hegemônico. Exemplos disso são a apologia do individualismo, o aumento do desemprego, da intensificação e da precarização do trabalho nos diferentes setores da economia.

Podemos pensar que, nos últimos anos, as perdas para a classe trabalhadora foram importantes não apenas do ponto de vista financeiro mas também de sua saúde física e psíquica. Não é por acaso que Sennet (1999) denominou de "corrosão do caráter" uma das principais conseqüências pessoais do modelo atual de organização do trabalho no capitalismo. A flexibilização trazida pela reestruturação produtiva - que exige trabalhadores ágeis, abertos a mudanças a curto prazo, que assumam riscos continuamente e que dependam cada vez menos de leis e procedimentos formais - não causa apenas sobrecarga de trabalho para os que sobreviveram ao enxugamento dos cargos, mas acarreta grande impacto para a vida pessoal e familiar de todos os trabalhadores; sejam eles empregados ou desempregados.

Os direitos sociais duramente conquistados pelos trabalhadores estão sendo substituídos ou subtraídos nos quatro cantos do mundo. O desemprego força as pessoas, desesperadas pela falta de dinheiro e de reconhecimento social, a enfrentarem filas aviltantes para tentar uma vaga no mercado do emprego formal, mesmo que este seja alienado e estranhado. Tragicamente, até mesmo o trabalho que pode comprometer a saúde física e psíquica passa a ser objeto de desejo.

Concordamos com Silveira (1989, p. 63) quando diz que "se é ridículo 'sentir nostalgia' das relações de dependência das formas pré-capitalistas, é também ridículo crer que "é preciso deter-se neste esvaziamento completo"" típico da universalização do estranhamento que se estabelece sob a lógica do capital.

\section{Notas}

\section{Cf. Seligmann-Silva (1994).}

2 Marx definiu o trabalho como “... um processo de que participam o homem e a natureza, processo em que o ser humano com sua própria ação impulsiona, regula e controla seu intercâmbio material com a natureza. Defronta-se com a natureza como uma de suas forças. Põe em movimento as forças naturais de seu corpo, braços e pernas, cabeça e mãos, a fim de apropriar-se dos recursos da natureza, imprimindo-lhes forma útil à vida humana. Atuando assim sobre a natureza externa e modificando-a, ao mesmo tempo modifica sua própria natureza." (Marx,1989a, p. 202). Cf. Thompson (2002).

4 Vale lembrar que é muito difícil entender o fordismo (que pressupõe também a produção e o consumo em massa) fora do contexto do americanismo: a propagação do fordismo exigiu uma nova forma de organização social do processo de produção que está intimamente ligada com o modo de viver e de ser do conjunto dos trabalhadores. Americanismo pode ser entendido como um conjunto de caracterizações próprias, originadas nos Estados Unidos que visam à construção de um Novo Homem para um novo tipo de trabalho. O modo de viver deve ser adaptado ao modo de produzir. O objetivo é criar um novo tipo de trabalhador (Gramsci, 1989).

5 Segundo Hirata (1994, p. 40) “os modelos sueco e italiano... podem ser caracterizados, conjuntamente, em oposição ao modelojaponês, como sendo modelos produtivos de envolvimento negociado dos trabalhadores nos novos processos de produção de qualidade e produtividade e só se realiza com sindicatos fortes e independentes. Tanto o modelo italiano quanto o sueco se apoiam numa formação profissional importante dos trabalhadores e na polivalência do trabalho em grupo. Embora tenham por objetivo, como todos os modelos industriais, alcançar a produtividade por meio de um máximo de eficiência, não se baseiam na produção enxuta."

6 Em referência direta ao nome do engenheiro Taiichi Ohno (19121990), a quem se atribui o mérito principal pela criação da 'nova escola japonesa', que teria sido originada na fábrica Toyota.

\section{Referências}

Antunes, R. (1995). Adeus ao trabalho? Ensaio sobre as metamofoses e a centralidade do mundo do trabalho. São Paulo, SP: Cortez.

Antunes, R. (1997). Trabalho, reestruturação produtiva e algumas repercussões no sindicalismo brasileiro. In R. Antunes (Ed.), Neoliberalismo, trabalho e sindicato: Reestruturação produtiva na Inglaterra e no Brasil (pp.71-84). São Paulo, SP: Boitempo.

Antunes, R. (1999) Os sentidos do trabalho. Ensaio sobre a afirmação e a negação do trabalho. São Paulo, SP: Boitempo.

Bosi, E. (1996). Simone Weil. A condição operária e outros estudos sobre a opressão. Rio de Janeiro, RJ: Paz e Terra.

Braverman, H. (1987). Trabalho e capital monopolista: A degradação do trabalho no século XX. Rio de Janeiro, RJ: Guanabara.

Coriat, B. (1994). Pensar pelo avesso: O modelo japonês de trabalho e organização. Rio de Janeiro, RJ: Editora da Universidade Federal do Rio de Janeiro. 
Decca, E. S. (1988). O nascimento das fábricas: Vol. 51. Tudoé História. São Paulo, SP: Brasiliense.

Gramsci, A. (1989). Americanismo e fordismo. In Maquiavel, a política e o Estado moderno (pp. 375-413). Rio de Janeiro, RJ: Civilização Brasileira.

Harvey, D. (1993). Condição pós-moderna. São Paulo, SP: Loyola.

Hirata, H. (1994). Novos modelos de produção, qualidade e produtividade. In Os trabalhadores e o Programa de Qualidade e Produtividade (pp. 38-54). São Paulo, SP: DIEESE.

Marglin, S. (1989). Origem e funções do parcelamento das tarefas (Para que servem os patrões?). In A. Gorz. (Ed.), Crítica da divisão do trabalho (pp. 37-77). São Paulo, SP: Martins Fontes.

Martins, J. A. (1994). A riqueza do capital e a miséria das nações. São Paulo, SP: Scritta.

Marx, K. (1989a). O capital, crítica da economia política: Vol. 1. Livro 1. Rio de Janeiro, RJ: Bertrand Brasil.

Marx, K. (1989b). Trabalho alienado e superação positiva da autoalienação humana. In F. Fernandes (Ed.), Marx/Engels: Vol. 36. Grandes Cientistas Sociais. História (pp. 146-181). São Paulo, SP: Ática.

Mészáros, I. (1989). Produção destrutiva e estado capitalista: Vol. 5. Ensaio. São Paulo, SP: Ensaio.

Ramalho, J. R. (1997). Precarização do trabalho e impasses da organização coletiva no Brasil. In R. Antunes (Ed.), Neoliberalismo, trabalho e sindicatos: Reestruturação produtiva na Inglaterra e no Brasil (pp. 85-113). São Paulo, SP: Boitempo.

Ranieri, J. (2001). A câmara escura: Alienação e estranhamento em Marx. São Paulo, SP: Boitempo.

Seligmann-Silva, E. (1994). Desgaste mental no trabalho dominado. São Paulo, SP: Cortez.

Sennet, R. (1999). A corrosão do caráter: As conseqüências pessoais do trabalho no novo capitalismo. Rio de Janeiro, RJ: Record.

Silveira, P. (1989). Da alienação ao fetichismo - Formas de subjetivação e de objetivação. In P. Silveira \& B. Doray (Eds.), Elementos para uma teoria marxista da subjetividade (pp. 41-76). São Paulo, SP: Vértice.

Thompson, E. P. (2002). Tempo, disciplina de trabalho e capitalismo industrial. In Costumes em comum. Estudos sobre a cultura popular tradicional (pp. 267-304). São Paulo, SP: Companhia das Letras.

Vera Lucia Navarro é graduada em Ciências Sociais pela Universidade Estadual de Londrina (UEL). Doutora em Ciências Sociais pela Universidade Estadual Paulista Júlio de Mesquita Filho. Docente da Universidade de São Paulo (USP) na Faculdade de Filosofia, Ciências e Letras de Ribeirão Preto, Departamento de Psicologia e Educação. Credenciada nos Programas de Pós-Graduação em Saúde na Comunidade, da Faculdade de Medicina de Ribeirão Preto/USP e Programa de Pós-Graduação em Psicologia da FFCLRP/USP. Sua produção científica é focada na Sociologia do Trabalho, com ênfase no estudo das relações entre trabalho e saúde. Autora do livro Trabalho e trabalhadores do calçado: a indústria calçadista de Franca (SP): das origens artesanais à reestruturação produtiva (Editora Expressão Popular, 2006). Endereço para correspondência: Universidade de São Paulo, Faculdade de Filosofia, Ciências e Letras de Ribeirão Preto, Departamento de Psicologia e Educação. Av. Bandeirantes, 3900, Ribeirão Preto, SP, CEP 14040-901. vnavarro@usp.br

Valquíria Padilha é Doutora em Ciências Sociais pela Universidade Estadual de Campinas (Unicamp). Doutorado Sanduíche realizado na Université de Bourgogne, França. Pós-Doutorado em Ciências Sociais pela Universidade Federal de São Carlos (UFSCar). Professora Doutora no Departamento de Administração da Faculdade de Economia, Administração e Contabilidade de Ribeirão Preto (FEA-RP) na Universidade de São Paulo (USP).

Autora do livro Shopping center: a catedral das mercadorias (Editora Boitempo, 2006) e organizadora de Dialética do lazer (Editora Cortez, 2006). Endereço para correspondência: Universidade de São Paulo, FEA-RP, Departamento de Administração. Av. Bandeirantes, 3900, Monte Alegre, Ribeirão Preto, SP, 14040-900. Telefone: (16) 36024468. valpadilha@fearp.usp.br

\section{Dilemas do Trabalho no Capitalismo Contemporâneo}

Vera Lucia Navarro e Valquíria Padilha

Recebido: 29/06/2006

$1^{\text {a }}$ revisão: 03/08/2006

$2^{\mathrm{a}}$ revisão: 07/12/2006

Aceite final: 26/12/2006 